\title{
An adjustable parameter water hammer wave hose testbench
}

\author{
Zhe Wang $^{1 *}$, Bensong Xia ${ }^{1}$, Xiajie Jing ${ }^{1}$, Keli Xing ${ }^{1}$ \\ ${ }^{1}$ School of Electronmechanical Engineering and Automation,Shanghai University,Shanghai, China
}

\begin{abstract}
In this paper, based on the servo valve controlled pressure cylinder, a scheme of hydraulic pipeline adjustable parameters water hammer wave test system is proposed. By changing the quality of pressure cylinder piston rod and controlling the opening of servo valve, the overshoot, pressure rise rate and oscillation of water hammer wave can be controlled. On this basis, based on AMESim simulation software, the paper studies the influence of different parameters of pressure cylinder and servo valve on water hammer wave, which provides the basis for the selection of main components. Finally, the experimental research is carried out on the designed system, and the results are consistent with the simulation results. The generated water hammer wave meets the requirements of the test standard, which proves that the hydraulic adjustable parameters water hammer test system developed in this paper is successful and feasible.
\end{abstract}

\section{Introduction}

When the hydraulic system is working, the sudden closing or opening of the valve will lead to the rapid change of oil flow rate, it will cause strong pressure impact in the pipeline, which is called water hammer phenomenon [1]. In the field of aerospace, the requirements for the impact resistance of hydraulic pipes are also higher and higher [2]. Therefore, the development of high-performance water hammer pulse test system is of great significance to meet the test requirements of high-quality and high-performance hydraulic pipelines.

\section{Test standard}

In order to study the characteristics of water hammer wave, according to the requirements of project partners, this paper studies based on the ARP603E Impulse Testing of Hydraulic Hose, Tubing, and Fitting Assemblies standard of Society of Automotive Engineers [3]. The water hammer test curve in the standard specification is shown in Figure 1, where $\mathrm{P}$ is the test pressure.

ARP603E stipulates that the maximum pulse peak value of the test is $125 \%$ and $150 \%$ of the rated working pressure respectively, and the pulse pressure waveform shall not exceed the shaded line range shown in Figure 1; the pressure rise rate shall be greater than $1225 \mathrm{MPa} / \mathrm{s}$.

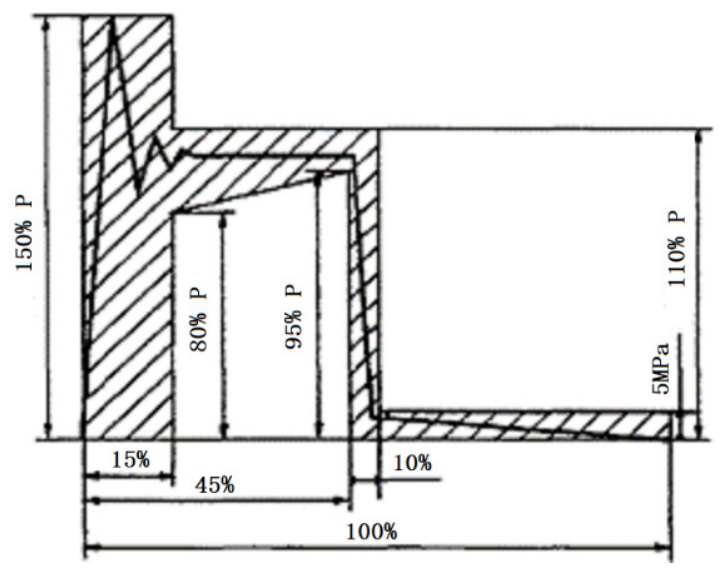

Figure 1. SAE standard water hammer pulse period curve

The calculation formula of water hammer overshoot is as follows:

$$
\sigma=\frac{p-p_{0}}{p_{0}} \times 100 \%
$$

The calculation formula of pressure rise rate of water hammer wave is as follows:

$$
k=\frac{0.9 p-0.1 p}{t_{1}-t_{2}}
$$

Where $\mathrm{P}$ is the peak pressure, $\mathrm{P} 0$ is the rated pressure, $\mathrm{t} 1$ is the time point of $90 \%$ peak pressure, $\mathrm{t} 2$ is the time point of $10 \%$ peak pressure.

\section{Test principe}

The hydraulic principle diagram of the test system is shown in Figure 2. 


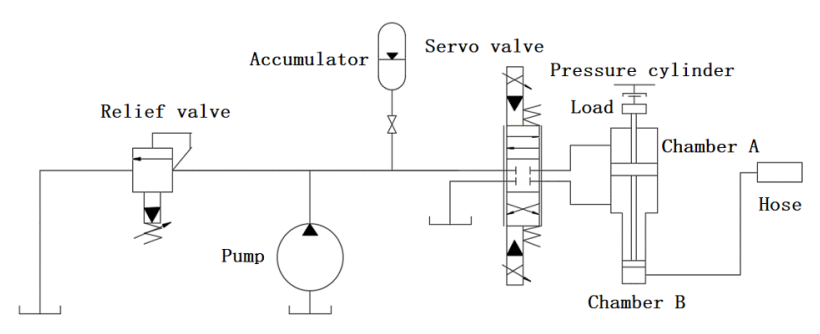

Figure 2. Schematic diagram of adjustable parameters water hammer test system

It can be seen from Figure 2 that adjust the relief valve at the outlet of the pump can set the pressure of the hydraulic system, and the reversing of the servo valve controls the reciprocating of the pressure cylinder piston to simulate the sudden closing and opening of the valve in the hydraulic system. This causes the oil to be compressed, so the pressure rises instantaneously, and propagates layer by layer along the opposite direction of the system [4]. Finally, due to the friction of the inner wall of the pipeline, the water hammer wave gradually attenuates with time until it disappears [5]. Here analyse two key factors.

\subsection{Influence of moving parts on pressure}

Let the inlet of the pressure cylinder is provided with a fixed pressure, when the servo valve is suddenly opened, the piston of pressure cylinder drives the load with mass of $m$ downward. Because of the inertia of the load, the pressure in cavity B will rise sharply, and the load with mass $m$ will decelerate due to the thrust generated by liquid in chamber B.

Assuming that the oil deceleration time is $t$, the velocity change is $\Delta \mathrm{v}$, and $\mathrm{A} 1$ is the piston area of chamber $\mathrm{B}$, then the pressure increment of chamber $\mathrm{B}$ is:

$$
\Delta p=\frac{m \cdot \Delta v}{A_{1} \cdot t}
$$

From the above analysis, it can be seen that the piston speed of the pressure cylinder and the mass of the load connected with the piston rod have an impact on the overshoot pressure $\Delta \mathrm{P}$ of the water hammer wave, and the overshoot pressure $\Delta \mathrm{P}$ increases with the increase of the momentum $\mathrm{m} \Delta \mathrm{v}$ of the load. Based on this analysis, this paper proposes to add an adjustable load on the piston rod on the basis of the original valve controlled pressure cylinder to control the momentum of the pressure cylinder.

\subsection{Influence of pressure cylinder on pressure}

In the pressure cylinder, Pascal's law states that a pressure change at any point in a confined incompressible fluid is transmitted throughout the fluid such that the same change occurs everywhere. Suppose the pressure of the piston on the chamber $\mathrm{A}$ is $\mathrm{P} 1$ and the diameter is $\mathrm{D}$, corresponding the chamber $\mathrm{B}$ is $\mathrm{P} 2$ and $\mathrm{d}$. Thus, it is concluded that:

$$
P_{1} \frac{\pi D^{2}}{4}=P_{2} \frac{\pi d^{2}}{4}
$$

Because of the incompressibility of the hydraulic oil, the pressure of the lower piston is much greater than that of the upper piston, so the area ratio of the two pistons also has an important relationship with the pressure.

\section{Simulation of test system}

In order to explore the influence of different parameters on the water hammer wave test system, this chapter uses the simulation and dynamic analysis software AMESim based on the bond graph to simulate the system [6]. The simulation system is built according to the water hammer test system shown in Figure 2, distributed parameter method is used in pipeline simulation [7]. The flow of the simulation system is set as follows: $0 \sim 10$ s main pump supplies pressure to accumulator, 10 13s simulation signal source is set to frequency $1 \mathrm{~Hz}$, that is, the water hammer wave test is carried out with a period of 1 second, and the simulation is completed after 13 seconds. The following is the simulation analysis of pressure cylinder and servo valve.

\subsection{Influence of pressure cylinder on water hammer wave}

The parameters in the system simulation model in Figure 2 are set as follows: the $80 \mathrm{ml} / \mathrm{r}$ main pump with $2000 \mathrm{rpm}$ and; the system relief valve is set at $7 \mathrm{MPa}$, and the pressure ratio is set to $1: 4$, that is, the test pressure is $28 \mathrm{MPa}$; accumulator with $5 \mathrm{~L}$ capacity, precharge pressure $5 \mathrm{MPa}$. The test object is a hose with an inner diameter of $22 \mathrm{~mm}$ and a length of $1000 \mathrm{~mm}$. The piston mass is changed as shown in the Figure 3.

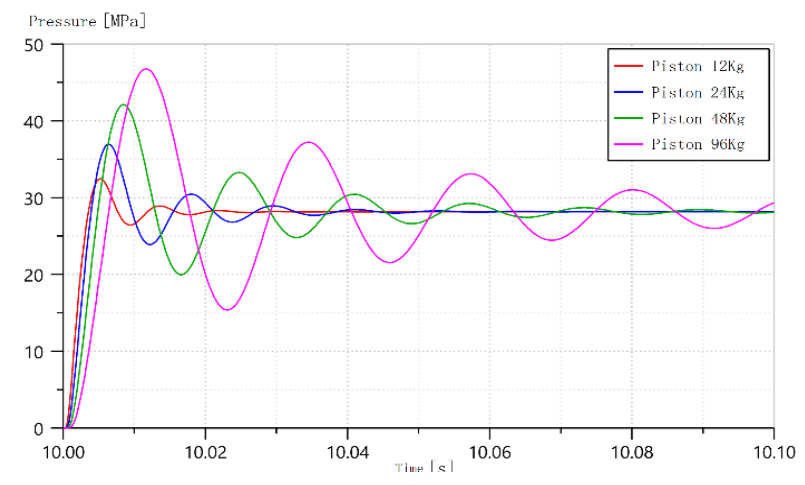

Figure 3. water hammer wave under different piston mass

The piston mass in this simulation model is set to $48 \mathrm{~kg}$, and the piston area of the pressure chamber is not changed. The piston diameter of the upper chamber of the pressure cylinder is changed to $65.05 \mathrm{~mm}, 92 \mathrm{~mm}$ and $112.68 \mathrm{~mm}$ respectively, that is, the pressurization ratio is 1:2, 1:4 and 1:6 respectively. The other parameters are set unchanged, and the simulation waveforms of water hammer wave under different pressurization ratios are obtained, as shown in the Figure 4. 


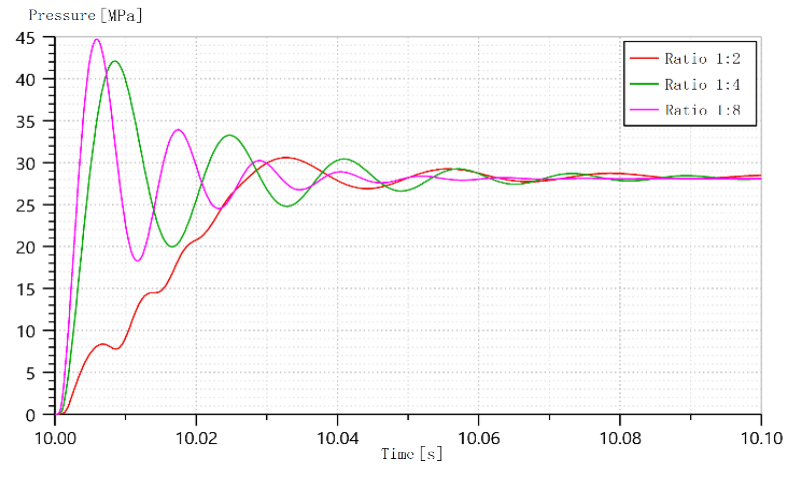

Figure 4. water hammer wave under different pressurization ratios

To sum up, when the piston mass is changed, the water hammer wave shape changes obviously. With the increase of piston mass, the peak pressure of water hammer wave increases, but after the peak value, the final stable pressure under different mass is consistent; When the area of the pressurization chamber is fixed, the larger the pressurization ratio of the pressure cylinder is, the smaller the overshoot of water hammer wave is, and the shorter the adjustment time is. The reason is the volume of the left chamber of the pressure cylinder becomes larger, which increases the damping of the system. Therefore, the pressure overshoot of the water hammer wave decreases and the adjustment time becomes shorter. Therefore, considering the pressure overshoot required by the water hammer test, as well as the rapidity and stability of the system response, the piston mass is selected as $48 \mathrm{~kg}$, and the pressurization ratio is selected as 1:4.

\subsection{Influence of servo valve on water hammer wave}

Combined with the above simulation results, the opening of servo valve is set to $0.4,0.7$ and 1 respectively for comparative simulation, and the other parameters remain unchanged, and the water hammer wave under different opening degrees of servo valve can be obtained, as shown in Figure 5.

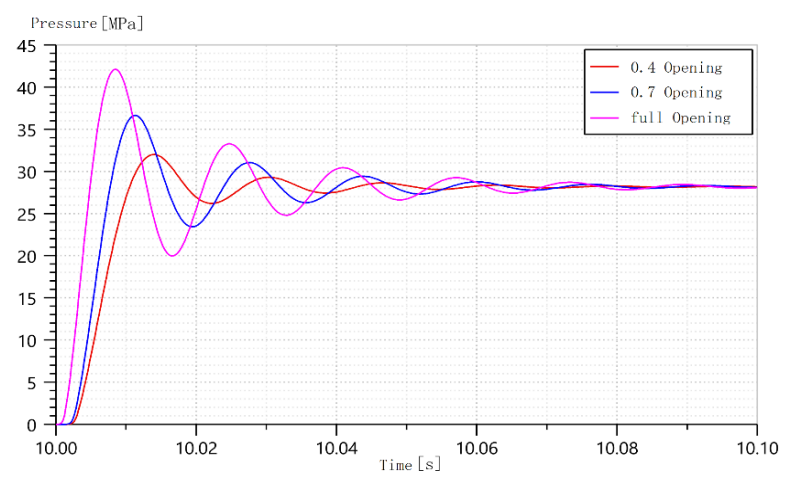

Figure 5. water hammer wave under different opening of servo valve

Set the diameter of the servo valve as $10 \mathrm{~mm}, 20 \mathrm{~mm}$ and $50 \mathrm{~mm}$, in other words, the flow pressure ratio of servo valve is $100 \mathrm{~L} /(\min \cdot 0.5 \mathrm{MPa}), 150 \mathrm{~L} /(\mathrm{min} \cdot 0.5 \mathrm{MPa})$ and $350 \mathrm{~L} /(\min \cdot 0.5 \mathrm{MPa})$. For comparative test, keep the valve port fully open, and other parameters remain unchanged. The obtained water hammer wave under different flow capacity of servo valve are shown in Figure 6.

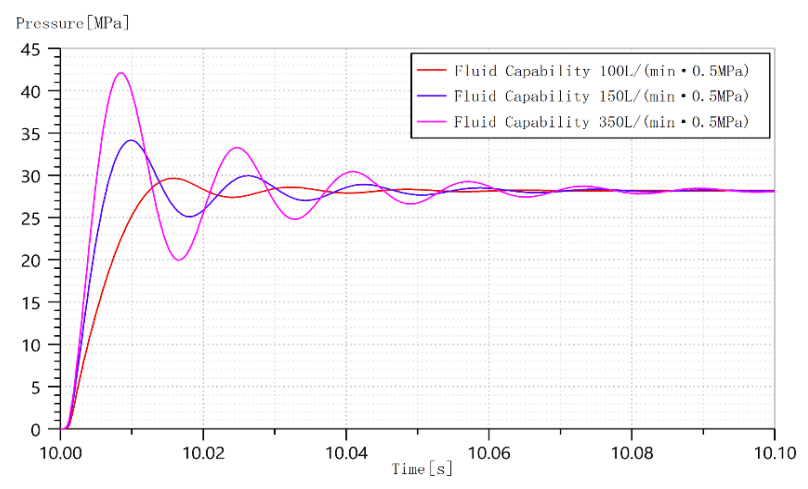

Figure 6. water hammer wave under different fluid capability of servo valve

The results show that the opening of the servo valve has an obvious influence on the water hammer wave. The larger the opening is, the greater the peak pressure of the water hammer wave is, and the faster the pressure rises. With the increase of the opening of the servo valve, the damping of the system becomes smaller, and the adjustment time of the system is also increased. The smaller the flow capacity of servo valve is, the smaller the pressure rise rate and pressure peak value of water hammer wave are. The reason is that the rated flow rate of servo valve is too low to let enough flow through at once, which limits the pressure rise rate and peak value of water hammer wave. For this system, when the flow pressure ratio of servo valve reaches $350 \mathrm{~L} /(\mathrm{min} \cdot 0.5 \mathrm{MPa})$, the water hammer wave can meet the requirements of the test standard.

\section{Test results and analysis}

Based on the simulation results and practical experience, the main hydraulic component parameters of the test device are as follows: $1: 4$ pressure cylinder; $80 \mathrm{ml} / \mathrm{r}$ main pump with 2000rpm; accumulator with 5L capacity, precharge pressure $5 \mathrm{MPa}$; throttle valve opening is 0.4 , and the test object is a hose with one meter long, $22 \mathrm{~mm}$ inner diameter. According to the test requirements, the test pressure of the hose is $28 \mathrm{MPa}$ and the test frequency is $1 \mathrm{~Hz}$. According to the SAE standard, the adjustment time of water hammer wave should be less than $15 \%$ of the cycle time. The test frequency is $1 \mathrm{~Hz}$, that is, the adjustment time should be less than $150 \mathrm{~ms}$.

Adjusting the external load mass to $24 \mathrm{~kg}$ and the opening of servo valve to 0.95 . The experimental results show that the parameters of water hammer waveform are overshoot $30.1 \%$, the pressure rise rate is $1368 \mathrm{MPa} / \mathrm{s}$, the peak time is $42 \mathrm{~ms}$, and the adjustment time is $99 \mathrm{~ms}$. The result is shown in Figure 7. 


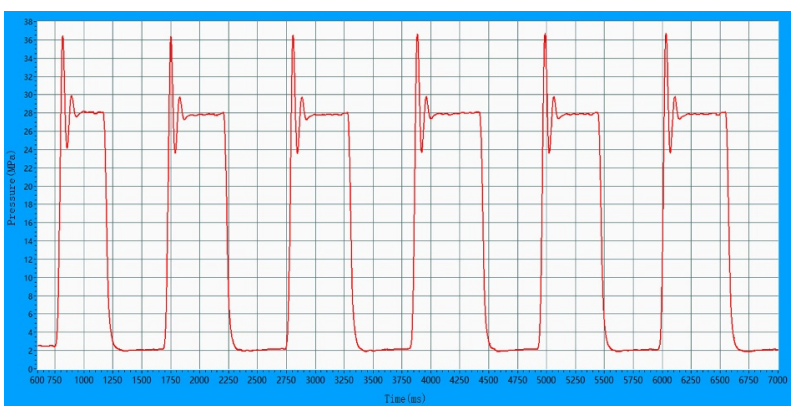

Figure 7. water hammer wave with $30 \%$ overshoot

Adjusting the external load mass to $64 \mathrm{~kg}$ and the opening of servo valve to 0.98 . The experimental results show that the parameters of water hammer waveform are overshoot $50.2 \%$, the pressure rise rate is $1317 \mathrm{Mpa} / \mathrm{s}$, the peak time is $54 \mathrm{~ms}$, and the adjustment time is $134 \mathrm{~ms}$. The result is shown in Figure 8.

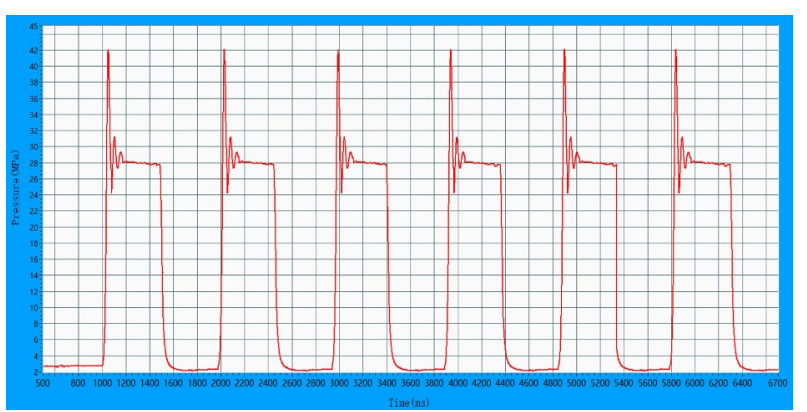

Figure 8. water hammer wave with $50 \%$ overshoot

According to the test requirements, the pressure rise rate of water hammer wave should be greater than $1225 \mathrm{MPa} / \mathrm{s}$, and the regulating time should be less than $150 \mathrm{~ms}$. Combined with the actual test results, the waveform of water hammer wave generated by the test system meets the standard. Also, by changing the mass of the piston rod and the opening of the servo valve, the water hammer wave with specified overshoot and regulating time can be generated, and the test waveform does not show large oscillation.

\section{Conclusion}

This paper based on the relevant standards uses the AMESim software to simulate the test system, which provides the basis for the selection of main components in the test system. On this basis, the test results show that by changing the different parameters of the servo cylinder and servo valve, the water hammer wave can present different waveforms. Also the overshoot, pressure rise rate and oscillation of the waveform can be effectively controlled. This proves that the development of the test system is successful.

\section{References}

1. Meng Ni. Study on water hammer protection scheme of pressure conduit many ups and downs inlong distance[D].Chang'An University, 2015.
2. Zhou Hong,Liu Yongtao,Shao Xiaojun,Yue Zhufeng. Shock response analysis of aircraft hydraulic pipeline $[\mathrm{J}]$. Aeronautical Computing Technique, 2010,40(04):1-3.

3. Impulse Testing of Hydraulic Hose, Tubing, and Fitting Assemblies[J], 2004.

4. Man Zaipeng. Generation and Application of Ultrahigh Pressure Hydraulic Impluse Waveform[D].ZheJiang University, 2015

5. Wang Chijun, The simulation of filter hydraulic pulse system based on AMESim[D]. South China University of Technology, 2012.

6. $\mathrm{Yu}$ Youguan,Gong Guofang,Hu Guoliang. Simulation technique of AMESim and its application in hydraulie system[J]. Hydraulics Pneumatics \& Seals, 2005(03):28-31.

7. Shan Changji. Comparison of the Mathematical Modeling for Two Hydraulic Pipeline Analysis Methods[J]. Journal of Jiamusi University (Natural Science edtion), 2013,31(06):936-938. 